observations of the comet of Halley at its appearance in 1607 ; his "Development of a general method for calculating the perturbations of comets "from his classical work on the great comet of 1807 , published at Königsberg in $18 \mathrm{ro}$, and somewhat difficult to meet with now, in its original form; the well-known memoir on the physical condition of Halley's comet with the plates, taken from Vol. 13 of the Astronomische Nachrichten; the memoir presented to the Berlin Academy in I824, entitled "Untersuchung der Theils der planetarischen Störungen, welcher aus der Bewegung der Sonne entsteht;" researches on the Saturnian system, the position of the plane of the rings and their dimensions, the figure and dimensions of the planet, the motions of the Huyghenian satellite and determination of the mass of Saturn therefrom, and the memoir on the theory of this system from Vol. 28 of the Astronomische Nachrichten; the Prize Essay "Untersuchung der Grösse und der Einflusses des Vörrucken der Nachtgleichen," to which was attached the motto, "Non frustra signorum obitus speculamur et ortus ;" various papers on precession, aberration, \&c., which appeared in the Tabulce Regiomentance, and elsewhere, and the essay on the "Scheinbare figur eines unvollstandig erleuchteten Planeten scheibe."

The portrait of Bessel after Mandel is prefixed, with reminiscences of his early life, from the correspondence with Olbers, and additional notes by the editor.

The work is entitled "Abhandlungen von Friedrich Wilhelm Bessel herausgegeben von Rudolf Engelmann, -Erster Band, Leipzig, I875."

\section{THE FLOWERING OF SPRING PLANTS*}

DRING the past twenty years the Scottish Meteorological Society has been collecting data relative to the budding, leafing, flowering, and defoliation of trees and plants, and to the migrations of birds in connection with the periodical return of the seasons, and it was proposed some time ago to discuss the material which has been accumulated. As preliminary, however, to this very difficult line of inquiry, it was resolved to discuss in the first place the observations which have been made by Mr. $\mathrm{McNab}$ on the flowering of spring plants in the open air in the Edinburgh Royal Botanic Garden during the past twenty-six years, and which have been published in the Transactions of the Botanical Society of Edinburgh. These observations have been made by the same observer on the same plants, growing in the same situations, during the whale of the twenty-six years.

The average day of flowering of thirty-two spring flowers has been determined, of which the following are examples:-Galanthus nivalis, Jan. 25; Eranthis hyemalis, Jan. 30 ; Hepatica triloba, Jan. $3 \mathrm{I}$; Corylus Avellava, Feb. 2; Rhododendron atrovirens, Feb. 3 ; Crocus susianus, Feb. 4 ; Leucojum vernum, Feb. Io; Daphne Mezereum, Feb. 22 ; Narcissus pumilus, March 1o ; Orobus vernus, March II; Muscari botryoides, March 18 ; Ribes sanguineum, March 22; Narcissus pseudo-Narcissus, March 31 ; and Fritillaria imperialis, April I.

The lateness or earliness of the different springs, as determined from the times of flowering of the thirty-two plants in each year, is considerable. The latest spring was 1855 , which was thirty days later than the average, and the earliest I 874 , which was twenty-three days earlier, thus giving a difference of fifty-three days between the latest and earliest springs during the past twenty-six years. As regards particular flowers, the deviations are much greater. The largest deviations from the average dates of flowering occur before the time of the equinox, when deviations of from five to seven weeks either way are of repeated occurrence; but after the equinox the Abstract of a paper read before the Edinburgh Botanical Society on Meteorological Society. deviations are markedly less, seldom reaching three weeks.

The springs of $1855,1856,1857,1865$, and 1870 were late throughout; and on the other hand, the springs of I85I, I862, I863, I868, I869, I872, and I874 were early throughout. Great variations have occurred in other springs, such as 1864 , which, being preceded by a very mild December, many spring plants came into fower in the end of 1863 . But in January the temperature was $2^{\circ} \circ$ under the average, and in February, $5^{\circ} \cdot 2$, and vegetation was consequently arrested. March was also under the average, and the weather did not improve till April 3, the mean temperature of this month being $\mathrm{I}^{\circ} \cdot 7$ above the average. The disturbing influence of this abnormal weather on the dates of flowering was in some cases very great. Thus, Sisyrinchium grandiflorum flowers on the average eleven days earlier than Daphne Mezereum, but in I864 Daphne Mezereum did not come into flower till eighty-six days after Sisyrinchium grandiflorum had flowered. It is the occurrence of these disturbances which renders a long series of years necessary in order to arrive at a sufficiently close approximation to the true mean dates of flowering.

As regards Edinburgh, Jan. I I may be considered as the turning point in the winter temperature, since previous to this date the temperature is, on the whole, falling, and after this date it continues steadily to rise.* Further, after this date the rainfall becomes less, clear weather is of more frequent occurrence, and the increase in the temperature is very largely due to an increase of sunshine. The extremely slow rate at which, up to the end of February, the mean temperature rises, and the small differences among the temperatures up to this date, and the large number of plants-fourteen in all out of thirtytwo-which come successively into flower during the interval, suggest that it is not so much absolute temperature that calls for consideration as the accumulated amounts of the preceding daily temperatures, in the extent to which these rise above freezing. The accumulated temperatures, thus calculated, are, for Galanthus nivalis, $72^{\circ} 7$, and G. plicatus, $146^{\circ} 4$; for Crocus susiantus, $125^{\circ} 2$, and $C$. vernus, $179^{\circ} 1$; for Rhododendron atrovireas, $120^{\circ} 3$, and $R$. Nobleanum, $249^{\circ} 3$; and for Narcissus pumilus, $347^{\circ} \mathrm{O}$, and $N$. pseudo Narcissus, $540^{\circ}$. . Similar data prepared for other places, in this and other countries, would be very instructive in showing how far the order of dates of flowering in Edinburgh is observed in other places, and what is the relation of the dates of flowering at each place to the accumulated temperatures at that place, and what modifications are brought about by purely climatic differences, particularly as these occasion different results as respects the heating and actinic rays of the sun.

The thirty-two plants, whose dates of flowering have been determined, include three varieties of one species, viz., the blue, white, and red varieties of Scilla bifolia. Of these three varieties the blue flowers first, viz., on March 7 ; next comes the white variety, on March I7; and lastly, the red variety, on March 21, the red being thus a fortnight later than the blue variety.

An interesting question may in this connection be raised with reference to the relation which the colours of flowers have to the dates of flowering. With this view, our British wild plants have been grouped according to the different colours of their flowers and the months in which the flowers usually first expand, the data being taken from Dr. Hooker's "Students' Flora of the British Islands." In classifying the plants, red includes pink, crimson, and scarlet; and green, all greenish-white, yellowish-green, and greenish-purple flowers. Grasses, carices, and other groups, characterised by inconspicuous floral envelopes, are excluded. The list examined includes 909 species, of which there are 257 with

* See Prof. Forbes's paper on the climate of Edinburgh, in Trans. Roy. Soc., Edin., vol, xxii. pp. 348 349. 
white flowers, 238 with yellow flowers, these two being nearly a half of the whole number; then follow red, I 44 ; purple, 94 ; blue, 87 ; green, $5 \mathrm{I}$; and miscellaneous, 38 . Taking each colour by itself, and calculating the percentages of that colour which has come into flower by each month from April to July, we obtain the following results for the first five classes:-

\begin{tabular}{lcrrrrrrrr} 
& & \multicolumn{1}{c}{ April. } & \multicolumn{1}{c}{ May. } & & June. & & July. \\
Blue .. & $\ldots$ & I6 & $\ldots$ & 43 & $\ldots$ & 7 r & $\ldots$ & 93 \\
White & $\ldots$ & I4 & $\ldots$ & 36 & $\ldots$ & 70 & $\ldots$ & 97 \\
Purple & $\ldots$ & 4 & $\ldots$ & 28 & $\ldots$ & 6 r & $\ldots$ & 92 \\
Yellow & $\ldots$ & 9 & $\ldots$ & 24 & $\ldots$ & $6 \mathbf{r}$ & $\ldots$ & 93 \\
Red ... & $\ldots$ & 9 & $\ldots$ & 25 & $\ldots$ & 62 & $\ldots$ & 94
\end{tabular}

Thus of these colours, the blues are, on the average, considerably the earliest in flowering; then follow in order the whites and the purples, and lastly the yellows and reds. It follows that the plants included in the British flora clearly tend to arrange themselves, as regards the dates of flowering, in the order of the colours of the spectrum, the average earliest being those which are nearest the part of the spectrum where the actinic rays are at the maximum. It will be observed that the differently-coloured varieties of Scilla bifolia are in the same order of flowering of the plants of the same colours in the British flora. Accurate observations, continued from year to year, of the exact dates of flowering of different plants, and particularly of differently-coloured. varieties of the same species, could not fail to contribute valuable data to the inquiry referring to the influence of the solar rays, in the development of the more important of the vital functions of plants in different seasons. Whilst it is quite true, as has been pointed out by Mr. R. A. Pryor in NATURE (vol. xiii. p. I 50), that flowers of all colours bloom in any of the spring or summer months, it is plain that it is only the method of inquiry by averages that can guide us in the search for the law or laws which regulate the seasonal distribution of colour among flowers. It is scarcely necessary to refer to the importance of this question in its possible applications in the rearing of early and late varieties of flowers and fruits.

ALEXANDER BUCHAN

\section{THE WORK OF THE "CHALLENGER" AND THE "VALOROUS"}

THE Admiralty have just issued Reports on the Soundings and Temperatures taken by the Challenger in the Pacific, and by the Valorous during her voyage out with the Arctic Expedition and home again.

Captain Thomson's Report is dated from Honolulu, August 8, 1875, and refers to operations in the Inland Sea and to the section from Yokohama to Honolulu. After some days' cruising in the Inland Sea in May, Captain Thomson returned to Yokohama, nothing of interest to the scientific branch having been obtained. The deepest water found in the longitudinal section during the voyage to Honolulu was 3,980 fathoms, whilst that from the turning-point at $156^{\circ}$ west longitude down to Honolulu was 3,025 fathoms. The bottom of this section of the North Pacific showed on nearly every occasion red clay, with manganese and pumice-stone in great quantities; the latter greatly increased as the approach to the Sandwich Islands was made.

Staff-Commander Tizzard makes his preliminary Report on the Temperatures of the North Pacific. From Samboangan nineteen soundings and serial temperatures were obtained in the western part of the North Pacific, from which two sections have been constructed, one from the Meangis Islands to the Admiralty Islands, and the other from the latter to Japan. It was found that when the depth exceeded 1,500 fathoms, the thermometer which regulated the bottom temperatures gave the same results as they did at $\mathrm{I}, 400$ fathoms, viz. $34^{\circ} 4$ (corrected). At a little to the southward of Tongatabu, the bottom temperature was $32^{\circ} 9$, and as the U.S. officers appear to have obtained colder temperatures at the bottom than any yet obtained by the Challenger in the North Pacific, Commander Tizzard thinks it probable that the bed of the Pacific is divided into at least three dtep basins by ridges of a not greater depth than $\mathrm{I}, 400$ fathoms from the surface. In the southern part of the western portion of the North Pacific the surface-temperature varied from $80^{\circ}$ to $84^{\circ}$, and that in February and March, considerably higher than any yet registered by the Challenger in the open ocean.

The Report contains a table of the soundings in the above sections, and four beautifully-constructed sectional charts. The two first show the soundings and isothermal lines from the Meangis to the Admiralty Islands, and between the latter and Japan. The third is intended to illustrate Staff-Commander Tizzard's remarks on the surface temperature of the section referred to above; and the fourth shows the soundings and isothermal lines between Nosema Head, Japan, and the I8oth meridian. One of the most notable features of these charts is the occasional sudden increase in depth; between Japan and the Admiralty Islands, for example, the bottom sinks at one place all at once from about 2,000 fathoms, on both sides, to a depth of 4,500 fathoms.

The Valorous on her outward voyage took nineteen soundings in Davis' Straits between $63^{\circ} 45^{\prime}$ and $68^{\circ} 57^{\prime} \mathrm{N}$. lat., the depth being found to vary from 58 to 200 fathoms. The bottom was mostly fine grey sand, mixed with shells, gravel, and stones. On returning south, lower soundings were obtained along the Greenland coast, with much the same results as to bottom. On getting clear of Cape Farewell the course was shaped to cross the Atlantic Ocean between the parallels of $59^{\circ}$ and $55^{\circ}$, and to join the soundings west ward of Ireland obtained in the Porcupine in 1862. The greatest depth obtained was 1,860 fathoms in lat. $57^{\circ} 50^{\prime} \mathrm{N}$., and $44^{\circ} 52^{\prime}$ W. long., with a bottom of Globigerina ooze, and a bottom temperature of $33^{\circ} 4$. In $56^{\circ}$ I I $\mathrm{N}$. lat. and $37^{\circ} 4 \mathrm{I}^{\prime} \mathrm{W}$. long. a depth of I,450 fathoms was obtained, the bottom Globigerina ooze, and next day in lat. $56^{\circ} I^{\prime} \mathrm{N}$., long. $34^{\circ} 42^{\prime} \mathrm{W}$, a submarine ridge of 690 fathoms was sounded on with the same description of bottom. On the day following this, in lat. $55^{\circ} 58^{\prime}$, long. $3 \mathrm{I}^{\circ} 4 \mathrm{I}^{\prime} \mathrm{W}$., the depth increased to I,230 fathoms, mud; the deep sounding of this day and that of the second day previous being equidistant ( $\mathrm{IO}_{3}$ miles) from the intervening shoaler ridge of 690 fathoms. On reaching the 26 th meridian of W. long., a westerly gale commenced, which prevented further proceedings. Globigerina ooze, with occasional fine sand and mud, are the main characteristics of this section. Two sectional charts exhibit graphically the data obtained.

\section{SCIENCE IN GERMANY}

(From a German Correspondent.)

M PULUJ, of Fiume, has recently published a de. N. scription of a school-apparatus for determining the mechanical equivalent of heat. The apparatus is of very simple construction, and consists of a calorimetrical and a dynamometrical part, which is connected with a rotating arrangement, such as may be found in any physical laboratory.

The calorimetrical part of the apparatus is formed of two truncated hollow cones of cast iron, fitting the one into the other. The inner one, $a$, does not quite reach to the bottom of the outer, $b$, and it projects a little above it. The outer cone, $b$, can be fixed, coaxially, into the spool of the driving machine. The inner cone contains mercury. If, now, the driving machine be set a-going and the inner cone held fast, heat is produced through friction of the touching surfaces of the cones.

For measurement of the work transformed into heat, the arrangement is as follows:--To the wooden lid, $e$, of 